\title{
Assessment of trauma scoring systems in patients subjected to exploratory laparotomy
}

\section{Avaliação dos escores de trauma em pacientes submetidos à laparotomia exploradora}

Mariana Kumaira Fonseca, AsCBC-RS1 (i); Ledwyng David González Patino"; Carlos Eduardo Bastian da-Cunha, AsCBC-RS'; Neiva Baldissera, ACBC-RS'; Antônio Rogério Proença Tavares Crespo, tCBC-RS'; Ricardo Breigeiron, tCBC-RS'; Jader Gus, ACBC-RS 1

\section{A B S T R A C T}

\begin{abstract}
Objective: to assess the epidemiological profile of patients undergoing exploratory trauma laparotomy based on severity and prognosis criteria, and to determine the predictive accuracy of trauma scoring systems in terms of morbidity and mortality. Methods: retrospective cohort study and review of medical records of patients undergoing exploratory laparotomy for blunt or penetrating trauma at the Hospital de Pronto Socorro de Porto Alegre, from November 2015 to November 2019. Demographic data, mechanism of injury, associated injuries, physiological (RTS and Shock Index), anatomical (ISS, NISS and ATI) and combined (TRISS and NTRISS) trauma scores, intraoperative findings, postoperative complications, length of stay and outcomes. Results: 506 patients were included in the analysis. The mean age was $31 \pm 13$ years, with the majority being males (91.3\%). Penetrating trauma was the most common mechanism of injury (86.2\%), predominantly by firearms. The average RTS at hospital admission was $7.5 \pm 0.7$. The mean ISS and NISS was $16.5 \pm 10.1$ and $22.3 \pm 13.6$, respectively. The probability of survival estimated by TRISS was $95.5 \%$, and by NTRISS $93 \%$. The incidence of postoperative complications was $39.7 \%$ and the overall mortality was $12.8 \%$. The most accurate score for predicting mortality was the NTRISS (88.5\%), followed by TRISS, NISS and ISS. Conclusion: the study confirms the applicability of trauma scores in the studied population. The NTRISS seems to be the best predictor of morbidity and mortality.
\end{abstract}

Keywords: Trauma Severity Indices. Laparotomy. Abdominal Injuries. Multiple Trauma.

\section{INTRODUCTION}

$\mathrm{T}$ rauma scores are classification systems quantified by numerical values that stratify the severity of injuries resulting from trauma, allowing a prognostic estimation in terms of morbidity and mortality'. These classifications are fundamental elements of trauma databases and registries, which enable quality assessment of the healthcare system².

The trauma scoring systems most used today are divided into three categories, according to the parameters considered in the score and calculation: anatomical, based on the location and extent of the injury, such as the Injury Severity Score (ISS), the New Injury Severity Score (NISS) and Abdominal Trauma Index (ATI); physiological, evaluated according to the patient's functional parameters, such as the Revised Trauma Score (RTS) and the Shock Index (SI); and mixed, which combine anatomical and physiological systems, such as TRISS (Trauma Injury Severity Score) and NTRISS (New Trauma Injury Severity Score) $)^{3,4}$. Due to the limitations of prognostic measurements particular to each index, updates and new scoring systems are constantly evaluated in an attempt to improve the predictive capacity of injury severity.

The aim of this study is to analyze the epidemiological profile of patients undergoing exploratory laparotomy following trauma at the Hospital de Pronto Socorro de Porto Alegre based on severity criteria, and to determine the outcome prediction accuracy of trauma scores as to morbidity and mortality in our Institution.

1 - Hospital de Pronto Socorro de Porto Alegre, Serviço de Cirurgia Geral e do Trauma - Porto Alegre - RS - Brasil 


\section{METHODS}

This is a retrospective cohort based on a medical record review of all patients who underwent exploratory laparotomy for blunt or penetrating trauma at the Hospital de Pronto Socorro de Porto Alegre, from November 2015 to November 2019. Exclusion criteria included patients under fourteen years of age, non-traumatic laparotomies, iatrogenic injuries, and perforations of hollow viscera resulting from impalement or ingestion of corrosive agents.

The variables analyzed comprised demographic data, mechanism of injury, associated non-abdominal injuries, physiological, anatomical and combined scores, intraoperative findings, negative and nontherapeutic laparotomies, need for reintervention and/ or open abdomen, clinical and surgical postoperative complications, length of stay, and outcome.

All surgical interventions were classified according to intraoperative findings as: negative, in the absence of intra-abdominal injury; non-therapeutic, if the detected abdominal injuries did not require surgical repair (lacerations to solid organs, omentum and mesentery without active bleeding); therapeutic, in cases that surgical repair of the identified injury was necessary; and damage control, in cases of abbreviated laparotomy with delayed definitive treatment. The aspiration of hemoperitoneum and the mobilization of any viscera to explore the abdominal cavity were not considered therapeutic measures.

Postoperative complications were divided into the following categories: infectious, in cases of bronchopneumonia, empyema, intra-cavitary abscess, bloodstream or urinary tract infection; pulmonary, including ventilator-associated pneumonia, bronchoaspiration, acute respiratory distress syndrome, among others; digestive, in cases of dehiscence of anastomoses and fistulas of the gastrointestinal tract; surgical site occurences, such as seroma, hematoma, wound infection and evisceration; renal, in cases of kidney failure, with or without replacement therapy; and thromboembolic events, such as deep venous thrombosis, pulmonary thromboembolism, and mesenteric ischemia. The adapted Clavien-Dindo in trauma scale adapted for trauma was applied according to the algorithm described by Naumann et al. ${ }^{5}$ to classify postoperative complications according to their severity. The RTS was calculated by adding the Glasgow Coma Scale (GCS), systolic blood pressure (SBP) and respiratory rate $(\mathrm{RR})$ of the patient at hospital admission according to the formula RTS $=0.9368 \times \mathrm{GCS}+0.7326$ $\times$ SBP $+0.2908 \times$ RR6. The SI was computed as the ratio between $\mathrm{HR}$ and SBP, being an early indicator of hemorrhagic shock in trauma victims ${ }^{7}$. The ISS was obtained by scoring traumatic injuries according to the table of the Abbreviated Injury Score (AIS, 2015) ${ }^{8}$. The NISS has the same ISS calculation criteria, but it scores the three most severe injuries, regardless of the affected region?. The ATI score was based on the severity classification of the anatomical injury attributed to each intra-abdominal organ during laparotomy ${ }^{10}$. The probability of survival (Ps), estimated by TRISS was determined by the equation Ps $=1 /(1+e-b)$, where $e$ $=2.7183$ and $b=b 0+b 1 \times$ RTS $+b 2 \times$ ISS $+b 3 \times$ age where b0 to b3 are coefficients with different weights for blunt or penetrating trauma, and the age index is 0 in patients $<55$ years and 1 in $\geq 55$ years ${ }^{11}$. NTRISS uses the same calculation criteria as the TRISS, replacing ISS for NISS as the anatomical index ${ }^{12}$

Statistical analysis was carried out using the IBM SPSS $®$ software, version 24.0. Continuous variables were described as means and standard deviations or medians and interquartile ranges, and categorical variables using frequency tables in absolute numbers and proportions. The sample was divided into two study groups, survival and death, according to the outcome. Student's t-test for independent samples was performed to analyze continuous variables with normal distribution, and the Mann-Whitney $U$ test, for quantitative variables with asymmetric distribution. Chi-square and the Fisher's exact tests were applied in the analysis of categorical variables. Binary logistic regression analysis was performed to assess risk factors, with description of the sensitivity, specificity and accuracy of the predictive models using the ROC curve. The significance level of $5 \%(p<0.05)$ was considered statistically significant.

The project was approved by the Ethics in Research Committee of the County Health Secretariat of Porto Alegre under the registration number 3,641,331. 


\section{RESULTS}

During the study period, 506 victims of abdominal trauma underwent exploratory laparotomy at the General and Trauma Surgery Service of the Hospital de Pronto Socorro de Porto Alegre. The mean age was $31 \pm 13$ years, with a predominance of males (91.3\%; $n=462$ ) and previously healthy individuals $(90.1 \% ; n=56)$. Penetrating trauma was the most common mechanism of injury $(86.2 \%$; $n=$ $436)$, the majority due to gunshot wounds $(60.7 \%$; $\mathrm{n}=307$ ). Two male patients were included twice in the series, as they were victims of penetrating trauma in different moments. There were associated nonabdominal injuries in $57.3 \%$ of the patients $(n=290)$, more frequent in the extremities $(30.6 \% ; n=155)$ and thorax (28.6\%; $n=145)$.

Regarding intraoperative findings, the most affected organs in penetrating injuries were small bowel, colons, liver and stomach, whereas in blunt trauma, spleen, kidney, small bowel, mesentery, and bladder lacerations predominated. The rate of negative laparotomies was $7.3 \%(n=37)$ and nontherapeutic ones, $6.7 \%(n=34)$. Thirty-two patients (6.3\%) underwent damage control surgery due to hemodynamic instability and/or coagulopathy. Baseline and operative characteristics are described in Table 1.

The mean RTS at hospital admission was 7.5 \pm 0.7 , and calculation was not possible in 23 cases in which endotracheal intubation was performed during prehospital care, making it impossible to obtain the value of GCS and spontaneous RR at hospital admission.

The average score of ISS and NISS was 16.5 \pm 10.1 and $22.3 \pm 13.6$, respectively, which suggests a profile of severe anatomical injuries (ISS/NISS $>15$ ). The NISS value was greater than the ISS in $56 \%(n=284)$ of the cases. The probability of survival was $95.5 \%$ when estimated by TRISS, and 93\% based on NTRISS calculation criteria.

The average Shock Index was $0.82 \pm 0.4$, a value above the threshold of 0.7 defined as normal. ATI was greater than 25 in $15 \%(n=78)$ of cases. All scores analyzed but ATI showed a statistically significant difference when stratified by the mechanism of injury, blunt trauma being more severe (Table 2 ).
Table 1. Baseline and operative characteristics of the sample.

Baseline and operative characteristics

n

\begin{tabular}{lc}
\hline Genre & \\
Male & $462(91.3)$ \\
Female & $44(88.7)$ \\
\hline Age (years) & $31 \pm 13$ \\
\hline Penetrating trauma & $(14-80)$ \\
Gunshot wound & $436(86.2)$ \\
Stabbing wound & $307(60.7)$ \\
\hline Blunt trauma & $129(25.5)$ \\
Traffic accident & $70(13.8)$ \\
Pedestrian struck & $41(8.1)$ \\
Physical assault & $9(1.8)$ \\
Fall from height & $9(1.8)$ \\
Struck blunt object & $7(1.4)$ \\
\hline Associated non-abdominal injury & $4(0.8)$ \\
Extremities & $290(57.3)$ \\
Thorax & $155(30.6)$ \\
Spinal cord injury & $145(28.6)$ \\
Traumatic brain injury & $39(7.7)$ \\
Face & $30(5.9)$ \\
Pelvis & $23(4.6)$ \\
Neck & $13(2.6)$ \\
\hline Laparotomy & $10(1.9)$ \\
\hline Nherapeutic & \\
Non-therapeutic & $403(79.6)$ \\
Damage control & $37(7.3)$ \\
\hline & $34(6.7)$ \\
& $32(6.3)$ \\
\hline & \\
\hline
\end{tabular}

The rate of postoperative complications was $39.7 \%(n=201)$, and infectious ones were the most common, mainly due to intracavitary abscesses, bronchopneumonia, and surgical site infections. Most complications were classified as minor (grade II, according to the adapted Clavien-Dindo classification ${ }^{5}$ ) and, therefore, managed only with supportive measures and pharmacological treatment, without the need for an invasive approach. There was no statistically significant difference between the incidence of 
complications and mechanism of injury. Patients with ATI > $25(15 \% ; n=78)$ developed a significantly higher rate of complications $(51.3 \%$ and $37.6 \%$, respectively; $p=0.03)$.

Table 2. Trauma indexes stratified by injury mechanism.

\begin{tabular}{|c|c|c|c|c|}
\hline Scores & $\begin{array}{l}\text { Blunt trauma } \\
\qquad(\mathrm{n}=70)\end{array}$ & $\begin{array}{l}\text { Penetrating Trauma } \\
\qquad(\mathrm{n}=436)\end{array}$ & $\begin{array}{c}\text { Total } \\
(n=506)\end{array}$ & $\mathrm{p}$ \\
\hline RTS & $7.2 \pm 1.1$ & $7.6 \pm 0.6$ & $7.5 \pm 0.7(0.98-7.84)$ & 0.005 \\
\hline ISS & $23.0 \pm 12.1$ & $15.4 \pm 9.4$ & $16.5 \pm 10.1(1-59)$ & 0.001 \\
\hline NISS & $27.0 \pm 14.7$ & $21.5 \pm 13.3$ & $22.3 \pm 13.6(1-66)$ & 0.002 \\
\hline ATI & $13.4 \pm 9.4$ & $13.1 \pm 11.3$ & $13.1 \pm 11(0-60)$ & $\mathrm{n} / \mathrm{s}$ \\
\hline TRISS & $89.2 \pm 19.6$ & $96.5 \pm 7.3$ & $95.5 \% \pm 10.2(4.7-99.7 \%)$ & 0.003 \\
\hline NTRISS & $86.3 \pm 22.5$ & $94.0 \pm 12.2$ & $93.0 \% \pm 14.3(1-99.7 \%)$ & 0.006 \\
\hline SI & $1 \pm 0.4$ & $0.7 \pm 0.3$ & $0.82 \pm 0.4(0.1-3.75)$ & 0.001 \\
\hline
\end{tabular}

* $\mathrm{n} / \mathrm{s}=$ not statistically significant.

In $18 \%$ of cases $(n=91)$, surgical reintervention was required to manage complications, and open abdomen was indicated in 62 individuals (12.3\%). The median length of stay was eight days, indicating that half of the patients remained hospitalized for more than one week, with an average of $16 \pm 26$ days.

The overall mortality was $12.8 \%(n=65)$, with no significant difference between blunt and penetrating trauma. The outcomes are presented in detail in Table 3.

The multivariate analysis of the baseline and operative characteristics and outcomes stratified by survival established risk factors for mortality in the studied population, as shown in Table 4. Variables such as age, injury to more than two intra-abdominal organs, vascular injuries, non-abdominal associated injuries, tachycardia, hypotension, altered level of consciousness, need for surgical reintervention, and open abdomen, as well as all the trauma scores evaluated, showed a statistically significant difference between the survival and death groups.

The predictive accuracy of trauma severity indices is described by the ROC curve in Figure 1. The score with the best predictive accuracy for this cohort of patients was NTRISS, followed by TRISS, NISS and ISS, all of which had an area under the curve (AUC) greater than 0.8. The RTS, ATI and SI indices showed a more limited predictive capacity, the SI being the system with the lowest accuracy among the evaluated scores.

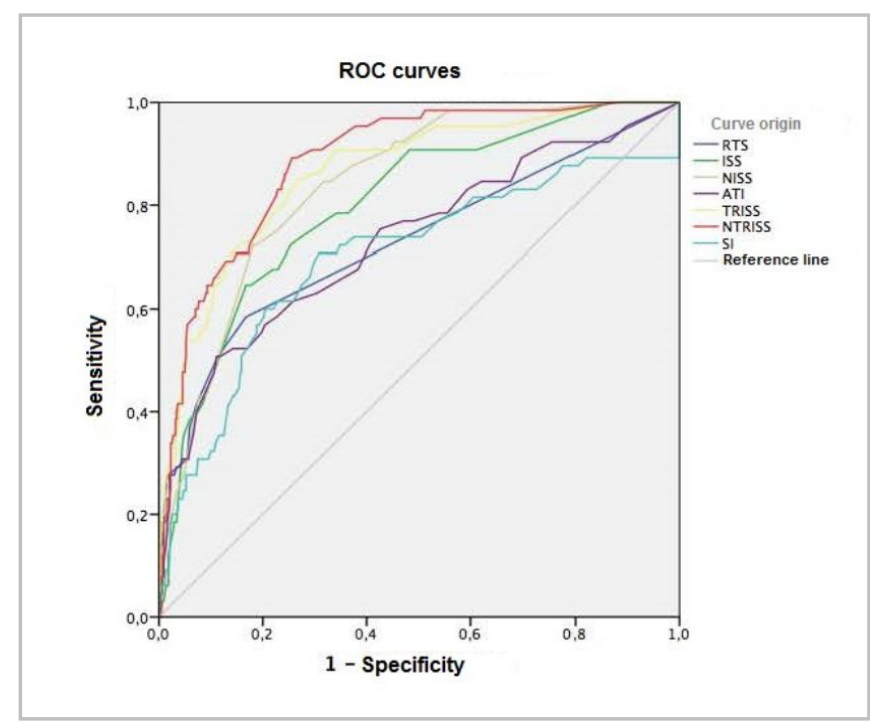

Figure 1. Analysis of predictive accuracy of trauma scores. 
Table 3. Postoperative complications and outcomes.

\begin{tabular}{|c|c|}
\hline Outcomes & $\mathrm{n}$ \\
\hline \multicolumn{2}{|l|}{ Complications (\%) } \\
\hline None & $305(60.3)$ \\
\hline Infectious & $144(28.4)$ \\
\hline Pulmonary & $46(9.1)$ \\
\hline Digestive & $44(8.7)$ \\
\hline Surgical site & $41(8.1)$ \\
\hline Renal & $32(6.3)$ \\
\hline Thromboembolic & $15(2.9)$ \\
\hline Total & $201(39.7)$ \\
\hline Clinical complication (\%) & $134(26.5)$ \\
\hline Bronchopneumonia & $51(10)$ \\
\hline Ventilator-associated pneumonia & $43(8.5)$ \\
\hline Acute renal failure & $36(7.1)$ \\
\hline Septic shock & $21(4.1)$ \\
\hline Urinary tract infection & $14(2.7)$ \\
\hline DVT / PTE & $9(1.7)$ \\
\hline Gastrointestinal bleeding & $7(1.4)$ \\
\hline Alithiasic cholecystitis & $3(0.6)$ \\
\hline Others (pancreatitis, endocarditis, & $10(1.9)$ \\
\hline colitis, spondylodiscitis...) & 135 \\
\hline Surgical complication (\%) & $135(26.7)$ \\
\hline Abscess & $59(11.6)$ \\
\hline Surgical site infection & $33(6.5)$ \\
\hline Anastomotic dehiscence/intestinal fistula / peritonitis & $30(5.9)$ \\
\hline Biliary fistula / bilioma/coleperitoneum & $11(2.1)$ \\
\hline Pancreatic fistula & $10(1.9)$ \\
\hline Evisceration & $10(1.9)$ \\
\hline Missed / iatrogenic injury & $9(1.7)$ \\
\hline Intestinal thrombosis / ischemia & $5(1.0)$ \\
\hline Urinary fistula & $5(1.0)$ \\
\hline Abdominal wall fasciitis & $2(0.4)$ \\
\hline Surgical reintervention (\%) & $91(18)$ \\
\hline Open abdomen (\%) & $62(12.3)$ \\
\hline Ostomy (\%) & $27(5.3)$ \\
\hline Length of hospital stay (days) & $\begin{array}{c}16 \pm 26 \\
(0-272) \\
\end{array}$ \\
\hline \multicolumn{2}{|l|}{ Mortality (\%) } \\
\hline General & $65(12.8)$ \\
\hline Penetrating trauma & $53(12.2)$ \\
\hline Blunt trauma & $12(17.1)$ \\
\hline
\end{tabular}


Table 4. Analysis stratified by survival.

\begin{tabular}{|c|c|c|c|}
\hline & $\begin{array}{l}\text { Survival Group } \\
\qquad(n=441)\end{array}$ & $\begin{array}{l}\text { Death Group } \\
\quad(n=65)\end{array}$ & $p$ \\
\hline Male & $405(91.8)$ & $57(87.7)$ & $n / s$ \\
\hline Age (years) & $30 \pm 12$ & $35 \pm 16$ & 0.034 \\
\hline Comorbidities & $40(9.1)$ & $10(15.4)$ & ns \\
\hline Injury $>2$ abdominal organs & $112(25.4)$ & $33(50.8)$ & $<0.001$ \\
\hline Abdominal vascular injury & $23(5.2)$ & $14(21.5)$ & $<0.001$ \\
\hline Associated non-abdominal injury & $239(54.2)$ & $51(78.5)$ & $<0.001$ \\
\hline Heart rate (bpm) & $90 \pm 21$ & $108 \pm 30$ & $<0.001$ \\
\hline Systolic blood pressure $(\mathrm{mmHg})$ & $122 \pm 27$ & $90 \pm 43$ & $<0.001$ \\
\hline Respiratory rate (rpm) & $20 \pm 4$ & $22 \pm 6$ & $n / s$ \\
\hline Glasgow Coma Scale & $14.6 \pm 1$ & $13.3 \pm 2.6$ & 0.001 \\
\hline RTS & $7.6 \pm 0.4$ & $6.7 \pm 1.5$ & \\
\hline ISS & $15 \pm 9.1$ & $26.7 \pm 10.7$ & \\
\hline NISS & $20 \pm 12.1$ & $37.7 \pm 13$ & \\
\hline ATI & $11.7 \pm 9.5$ & $23 \pm 14.8$ & $<0.001$ \\
\hline TRISS & $97.3 \pm 5.5$ & $83.4 \pm 21.2$ & \\
\hline NTRISS & $95.5 \pm 9.6$ & $75.7 \pm 25.4$ & \\
\hline SI & $0.78 \pm 0.3$ & $1.1 \pm 0.6$ & \\
\hline Open abdomen & $29(6.6)$ & $33(50.8)$ & $<0.001$ \\
\hline Reintervention & $64(14.5)$ & $27(41.5)$ & $<0.001$ \\
\hline
\end{tabular}

${ }^{\star} \mathrm{n} / \mathrm{s}=$ not statistically significant.

\section{DISCUSSION}

Trauma scoring systems are tools that allow an objective assessment of injury severity and universally predict the prognosis of traumatized patients ${ }^{1,13}$. This standardization contributes to the implementation of strategies in different areas, including assistance, quality monitoring, teaching, and research.

In daily practice, severity scores facilitate the identification of patients at increased risk of complications and death, therefore requiring better postoperative support in an attempt to prevent or promptly detect potential events $^{3,13}$. In terms of quality monitoring, outlining the clinical-epidemiological profile of the service and auditioning patient outcomes determine the effectiveness of the care provided, the optimization of hospital resources, and the identification of possible deficiencies ${ }^{12}$. In clinical investigation and research, the uniformization of medical records and trauma registries allows statistical comparison of institutional results with other established 
local, national, or international standards ${ }^{4}$.

The proposed scoring systems differ in terms of ease of calculation, predictive accuracy, advantages, and limitations, being continuously improved and revised to better serve their purpose. The scores assessed in this study have been validated as predictive instruments of morbidity and mortality by several publications. However, few authors ${ }^{1,13-15}$ have evaluated these severity indicators in the subgroup of patients undergoing surgical treatment by exploratory laparotomy.

A temporal comparison of the presented sample is possible thanks to Pruinelli et al. ${ }^{13}$, who, in the early $90 \mathrm{~s}$, conducted a study that evaluated the ATI in all patients undergoing exploratory laparotomy for trauma in our Institution. In one year, 468 patients were operated, of whom 285 were selected for sustaining isolated abdominal trauma - a proportion well above the 506 surgical cases distributed in the last five years of our analysis. The reduction in the number of operations is mainly due to the more precise indications of non-operative treatment in selected cases, both in blunt and in penetrating trauma.

The epidemiological profile of the Institution described 28 years ago $^{13}$ remains very similar to the present, with a predominance of young adult, male patients (92\% of cases; mean age 27 years), and penetrating trauma as the main mechanism (86\%), with a preponderance of gunshot wounds. The studies conducted by Fraga et al. ${ }^{1}$ (Campinas, 2004; $n=1380$ ) and Kruel et al. ${ }^{16}$ (Florianopolis, 2007; $n=185$ ) with patients undergoing trauma laparotomy reveal the same panorama. The involvement of young adult workers, in this context, represents a public health problem, due to both social and economic impact.

In contrast, international series differ from Brazilian findings regarding the proportion between sexes, age groups, and the most prevalent mechanism of injury. Van Gool et al. ${ }^{14}$, in the Netherlands, evaluated 92 trauma victims who underwent laparotomy, $71 \%$ of whom were men, with an average age of 37 years, and $64 \%$ sustaining blunt trauma, with only $16 \%$ of cases due to gunshot wounds. A North American study with 1,029 patients, published by Joseph et al. ${ }^{15}$, presented results similar to European ones, with predominance of males (82\%) of more advanced age (39 \pm 18 years) and sustaining blunt trauma $(61 \%)$. Also in the United States, Choi et al. ${ }^{17}$ reported 175 cases of therapeutic laparotomies, with $80 \%$ due to blunt trauma.

The intraoperative findings and most affected abdominal organs described in Table 1 are in accordance with the literature ${ }^{1,16}$ and the Institution's historical series ${ }^{13}$, with emphasis on hollow viscera, liver and spleen injuries. The combined negative and non-therapeutic laparotomies corresponded to $14 \%$ of the cases, which is very similar to that reported in other series (Kruel et al. ${ }^{16}, 14 \%$; Fraga et al. ${ }^{1}, 21 \%$; Choi et al. $\left.{ }^{17}, 21 \%\right)$. This proportion remained relatively stable when compared with 28 years ago (Pruinelli et al. ${ }^{13}, 16 \%$ ) - an unusual fact, considering the trend of reduction in negative and non-therapeutic laparotomies due to the evolution of diagnostic imaging and minimally invasive approaches. We assume that the less precise surgical indications in isolated wounds of solid viscera, in addition to the use of hemostatic sutures even in injuries without active bleeding may have overestimated the rate of therapeutic laparotomies at the time.

The proportion of damage control surgeries was $6.3 \%$, lower than international standards. In a multicenter study that included six level I trauma centers in the United States ${ }^{18}$, the ideal rate of abbreviated laparotomies was estimated between $13 \%$ and $27 \%$ of all trauma laparotomies. We found no Brazilian statistics for comparison.

The incidence of postoperative complications was relatively high $(39.7 \%)$, with a predominance of infections - in particular, intra-abdominal abscesses and bronchopneumonias -, followed by ventilator-associated pneumonia, surgical site occurences, and gastrointestinal dehiscences/fistulas. However, most complications were managed conservatively. The complication rate reported by the Institution in the 90 s was $22.1 \%{ }^{13}$, mainly infectious and pulmonary in etiology. Other series report variable but relatively high rates of early postoperative complications (Choi et al. ${ }^{17}, 81 \%$; Van Gool et al. ${ }^{14}, 66 \%$; Fraga et al. ${ }^{1}$, 42.4\%; Joseph et al. ${ }^{15}, 21 \%$ ).

Regarding mortality, the literature is quite heterogeneous. In our series, the death rate was $12.8 \%$, with no significant difference in relation to the mechanism of injury. Fraga et al. ${ }^{1}$ and Kruel et al. ${ }^{16}$ report similar Brazilian statistics, with $16.8 \%$ and $10.2 \%$ of fatal victims, respectively, but with significantly higher mortality rates in blunt trauma. In international publications, Choi et 
al. ${ }^{17}$, Joseph et al. ${ }^{15}$, and Van Gool et al. ${ }^{14}$ also describe similar results, with $13 \%, 15.7 \%$ and $17 \%$, respectively. Pruinelli et al. ${ }^{13}$, on the other hand, observed only a 3.1\% mortality rate, which could be justified by the selection bias determined by the exclusion of patients with associated non-abdominal injuries that may present a more severe systemic repercussion.

The present study confirms the applicability of trauma scoring systems in our Institution, despite the limitations inherent to each analyzed score. When comparing AUCS, the physiological scores (RTS and SI) showed a more limited discriminatory capacity for survival, with values $<0.8$. An increasing limitation to the calculation of RTS results from a rise in the number of endotracheal intubations and sedations in pre-hospital care, making it impossible to record the verbal response of the GCS and the spontaneous RR at hospital admission ${ }^{3}$. Other RTS measurement biases result from the constants used in the formula, which are smaller for SBP and RR and larger for GCS. Since the level of consciousness can be independently affected by the use of drugs, alcohol, and medications, the trauma circumstances can overestimate its severity. Similarly, younger patients with a higher physiologic reserve may take longer to display alterations in vital signs, situations in which the RTS tends to underestimate severity ${ }^{19}$.

$\mathrm{SI}$ is an early marker of hypovolemia and an alternative tool to the simple assessment of vital signs. Its average in the studied population was 0.82 , in line with recent studies that defined the cutoff point of 0.8 on admission as a predictor of the need for laparotomy ${ }^{20}$. Another application described in the literature is the use of SI intraoperatively in damage control surgeries, as a strong predictor of mortality if greater than $1.0^{21}$. We did not perform this measurement in the present study.

Among the anatomical scores, ATI had the worst performance, with a predictive accuracy of $73.1 \%$, versus AUC $>0.8$ for ISS and NISS. Furthermore, it was the only of the analyzed scores whose results did not display a statistical difference between blunt and penetrating trauma. Blunt trauma usually involves the dissipation and distribution of energy over a relatively larger surface area, and is therefore associated with potentially more serious injuries. ATI does not consider injuries in body segments other than the abdomen that can significantly contribute to morbidity and mortality ${ }^{1}$. Nevertheless, it was a good predictor of postoperative complications; values above the cutoff of 25 points were related to a higher incidence of complications, with statistical significance.

NISS values were higher than the ISS ones in more than half of cases (56\%), being an even better predictor of survival than the ISS. The latter ignores more than one potentially serious injury in the same body segment, to the detriment of less relevant injuries in other regions. This can underestimate the severity of certain patients with injuries restricted to one body region'. The NISS has the practical advantage of easier calculation, as it does not require the division of the body into regions, in addition to giving priority to injury severity, regardless of the affected area. Both indexes had an average value greater than 15 , underlining anatomical injuries considered severe.

The probability of survival greater than or equal to $50 \%$, which corresponds to preventable deaths, was estimated at $86.9 \%$ and $86.3 \%$ by TRISS and NTRISS, respectively, very similar to the $87.1 \%$ survival observed in the study. Mixed scores had the best predictive accuracy among all the other evaluated ones; the NTRISS had a slightly superior performance. The difference is only due to the higher anatomical score ${ }^{19}$, given that the physiological parameters and coefficients adjusted for age and mechanism of injury remain the same in the calculation. Despite the better results of NTRISS suggested by several studies $^{1,19}$, the community is still reluctant to adopt it, and TRISS remains the most used mixed index in the literature.

The main limitations of this study are its retrospective nature and those inherent to the use of medical records as a data source. Inconsistent documentation of vital signs and anatomical injuries may represent biases for the proper calculation of trauma scores. As an example, the RR did not have a statistically significant difference between the survival and death groups, despite being an early indicator of severity in the traumatized patient when altered.

In the context of trauma care, it is essential to train health professionals on the calculation and interpretation of severity scores as tools for therapeutic planning and service quality assessment. The improvement of instruments or the development of new ones that overcome the limitations of current systems is still an object of study. 


\title{
R E S U M O
}

\begin{abstract}
Objetivo: analisar o perfil epidemiológico dos pacientes submetidos a laparotomia exploradora por trauma com base em critérios de gravidade e prognóstico, e determinar a acurácia preditiva dos escores de trauma em termos de morbimortalidade. Métodos: estudo de coorte retrospectiva e revisão de prontuários dos pacientes submetidos a laparotomia exploradora por trauma contuso ou penetrante no Hospital de Pronto Socorro de Porto Alegre no período de novembro de 2015 a novembro de 2019. Foram avaliados dados demográficos, mecanismo do trauma, lesões associadas, índices fisiológicos (RTS e Shock Index), anatômicos (ISS, NISS e ATI) e mistos (TRISS e NTRISS), achados intraoperatórios, complicações pós-operatórias, tempo de internação e desfecho. Resultados: foram incluídos 506 pacientes na análise. A idade média foi de $31 \pm 13$ anos, com predomínio do sexo masculino (91,3\%). O trauma penetrante foi o mecanismo de lesão mais comum (86.2\%), sendo a maioria por arma de fogo. A média do RTS na admissão hospitalar foi 7,5 \pm 0,7. A média do ISS e do NISS foi 16,5 $\pm 10,1$ e 22,3 $\pm 13,6$, respectivamente. A probabilidade de sobrevida estimada pelo TRISS foi de 95,5\%, e pelo NTRISS de 93\%. A incidência de complicações pós-operatórias foi de 39,7\% e a mortalidade geral de 12,8\%. O escore com melhor acurácia preditiva foi o NTRISS (88,5\%), seguido pelo TRISS, NISS e ISS. Conclusões: o estudo confirma a aplicabilidade dos escores de trauma na população em questão. O NTRISS parece ser o sistema com melhor acurácia preditiva de morbimortalidade.
\end{abstract}

Palavras chave: Índices de Gravidade do Trauma. Laparotomia. Ferimentos e Lesões. Traumatismo Múltiplo.

\section{REFERENCES}

1. Fraga GP, Mantovani M, Magna LA. Índices de trauma em pacientes submetidos à laparotomia. Rev Col Bras Cir. 2004;31(5):299-306.

2. Champion HR, Sacco WJ, Copes WS, Gann DS, Gennarelli TA, Flanagan ME. A revision of the Trauma Score. J Trauma. 1989;29(5):623-9

3. Chawda M, Hildebrand F, Pape H, Giannoudis P. Predicting outcome after multiple trauma: which scoring system? Injury. 2004;35(4):347-58.

4. Lecky F, Woodford M, Edwards A, Bouamra O, Coats $\mathrm{T}$. Trauma scoring systems and databases. $\mathrm{Br}$ J Anaesth.2014;113(2):286-94.

5. Naumann DN, Vincent LE, Pearson N, Beaven A, Smith IM, Smith K, et al. An adapted Clavien-Dindo scoring system in trauma as a clinically meaningful nonmortality endpoint. J Trauma Acute Care Surg. 2017;83(2):241-8.

6. Champion HR, Copes WS, Sacco WJ. A new characterization of injury severity. J Trauma. 1990;30(5):539-45.

7. Cannon CM, Braxton CC, Kling-Smith M, Mahnken $J D$, Carlton E, Moncure M. Utility of the shock index in predicting mortality in traumatically injured patients. J Trauma. 2009;67(6):1426-30.

8. Association for the Advancement of Automotive Medicine. Abbreviated Injury Scale 2018, 2015 Revision. 6a ed. Chicago, IL.

9. Osler TM, Rogers FB, Badger GJ, Healey M, Vane DW, Shackford SR. A simple mathematical modification of TRISS markedly improves calibration. J Trauma. 2002;53(4):630-4.

10. Borlase BC, Moore EE, Moore FA. The Abdominal Trauma Index - a critical reassessment and validation. J Trauma. 1990:30(11):1340-4.

11. Champion HR. Trauma scoring. Scand J Surg. 2002;91(1):12-22.

12. Fraga GP. Programa de qualidade no atendimento ao trauma. Medicina (Ribeirão Preto). 2007;40(3):3218.

13. Pruinelli $R$, Souza HP, Cardoso AA, Stedile M, Pinto RD. Avaliação do índice de trauma abdominal (ATI): estudo prospectivo de 285 casos. Rev HPS. 1994;40(1):32-8.

14. van Gool MH, Giannakopoulos GF, Geeraedts LM Jr, Lange-de-Klerk ESM, Zuidema WP. Complications after laparotomy for trauma: a retrospective analysis in a level I trauma centre. Langenbecks Arch Surg. 2015;400(1):83-90.

15. Joseph B, Zangbar B, Khalil M, Kulyatunyou N, Haider AA, O'Keeffe T, et al. Factors associated with failure-to-rescue in patients undergoing trauma laparotomy. Surgery. 2015;158(2):393-8.

16. Kruel NFO, Valdriana LO, Oliveira VL, Honorato RD, Di Pinatti B, Leão FR. Perfil epidemiológico de trauma abdominal submetido à laparotomia exploradora. ABCD Arq Bras Cir Dig. 2007;20(2):106-10.

17. Choi KC, Peek-Asa C, Lovell M, Torner JC, Zwerling C, Kealey GP. Complications after therapeutic trauma laparotomy. J Am Coll Surg. 2005;201(4):546-53.

18. Harvin JA, Sharpe JP, Croce MA, Goodman MD, 
Pritts TA, Dauer ED, et al. Better understanding the utilization of damage control laparotomy: a multiinstitutional quality improvement project. J Trauma Acute Care Surg. 2019;87(1):27-34.

19. Domingues, CA, Nogueira LS, Settervall CHC, Sousa RMC. Desempenho dos ajustes do Trauma and Injury Severity Score (TRISS): revisão integrativa. Rev Esc Enferm USP. 2015;49(spe):138-46.

20. El-Menyar A, Peralta R, Latifi R, Consunji RJ, Al-Thani
H. Shock Index: a simple predictor of exploratory laparotomy and massive blood transfusion protocol in patients with abdominal trauma. J Am Coll Surg. 2018;227(4):e64.

21. Zangbar B, Joseph B, Ibraheem K, Kulvatunyou N, Tang $A$, O'Keeffe $T$, et al. Intra-operative Shock Index predicts mortality in patients undergoing damage control laparotomy [abstract]. In: Academic Surgical Congress Abstracts Archive. 2016;76:19.

Received in: 12/03/2020

\section{Mailing address:}

Accepted for publication: 01/06/2020

Mariana Kumaira Fonseca

Conflict of interest: no.

E-mail: marianakumaira@gmail.com

Funding source: none.

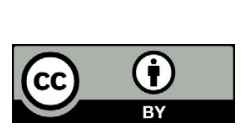

